peutic approaches was thus hypothesised. With the influx of 'newer' treatment modes, the enthusiasm had shifted away from psychotherapeutic to pharmacotherapeutic modes which were more 'mathematical' and 'objective'.

Since these modes were simpler and shorter, and their efficacy more measurable, clinicians started casting a doubt upon the usefulness of psychotherapy, not to mention its possible deleterious effects. The success of neuroleptics was, however, not the only reason for pessimism in psychodynamically orientated theories and therapies. The outcome studies in the field of psychotherapy only reinforced the fears of its demise (Stanton et al, 1984; Gunderson et al, 1984) and cautioned its readers about the inherent difficulties of undertaking research in this immensely popular research area in the early part of this century.

In the past, probably, research in this field has been overinclusive. Trying to explore and analyse every aspect of patients' psychopathology which was volunteered or exposed was neither cost effective nor productive. In contrast to psychotherapeutic research, pharmacotherapeutic research currently enjoys substantial grants since it somehow succeeds in halting the disease process, the management being shorter, simpler and target orientated. It is more acceptable although it is symptom orientated and lacks a definite aetiological hypothesis (the aetiology is suggested only because the drug works). Psychodynamic exploration and psychotherapeutic management, although seen with scepticism, happen to be assessment procedures which are actually based on a solid and stable aetiological hypothesis, and thus enjoy a distinct advantage over biological research. Abandoning such a potential area when the answers are still not available in biological psychiatry may be a serious omission.

It is encouraging to see the newer psychotherapeutic procedures becoming short term, target orientated and cost effective. If psychotherapy is to survive as a potentially useful management procedure in the future, such amendments are necessary.

Gunderson, J. G., Frank, A., KATZ, H. N., et al (1984) Effects of psychotherapy in schizophrenia: II. Comparative outcomes of two forms of treatment. Schizophrenia Bulletin, 10, 564-598.

Mueser, K. T. \& Berenbaum, H. (1990) Psychodynamic treatment of schizophrenia - is there a future? Psychological Medicine, 20, 253-262.

Ostrow, M. (1966) The complementary roles of psychoanalysis and drug therapy. In Psychiatric Drugs (ed. H. Solomon). New York: Grune \& Stratton.

Stanton, A. H., Gunderson, J. G., GnapP, P. H., et al (1984) Effects of psychotherapy in schizophrenia: I. Design and implementation of a controlled study. Schizophrenia Bulletin, 10, 520-563.
STRECKER, E. A. (1934) The practice of psychiatry. Archives of Neurological Psychiatry, 31, 410.

Department of Psychiatry

DiNeSh K. ARYA

University Hospital

Nottingham NG7 $2 U H$

\section{Child psychiatry in the 20th century (England \& Wales)}

SIR: The paper by Wardle (Journal, July 1991, 159, 53-58) misleadingly refers, in its title, to the development of services for child and adolescent psychiatry in Britain. The paper, in fact, refers to the development of these services in England and Wales; Scotland is ignored. There is no mention, in Table 6, of the Kilbrandon Report of 1964 and the subsequent Social Work (Scotland) Act of 1968 which led to the setting up of Children's Hearings. Similarly, this table ignores the report Crossing the Boundaries: New Directions in the Mental Health Services for Children and Young People in Scotland published in 1983. Perhaps the College could ensure in future that papers purporting to describe national developments should do just that: the alternative, as displayed in $\mathrm{Dr}$ Wardle's paper, is at best unsatisfactory and at worst offensive.

HMSO (1983) Crossing the Boundaries: New Directions in the Mental Health Services for Children and Young People in Scotland. Edinburgh: HMSO.

Tayside Health Board

HUGH G. MORTON

Child and Family Psychiatric Service

Area 2A, Polyclinic

Ninewells Hospital

Dundee DDI 9SY

\section{Evaluation of motor disorder in mentally handicapped} people

SIR: We welcome Jones' discussion (Journal, September 1991, 159, 441) of the evaluation of motor disorder in mentally handicapped people (MHP) and the DISCUS (Sprague et al, 1989).

There are numerous difficulties in any form of assessment of dyskinesia in severely and profoundly mentally handicapped people, the level of cooperation being only one of them. Others include: stress and anxieties caused by the examination, and exacerbated by the problems in verbal and nonverbal communication; the inability on the examiner's part to assess the individual's wishes and consent; the limited information of the mental state; and especially, mood on the day of rating. 